\title{
Osteometric Assessment of Various Mandibular Morphological Traits for Sexual Dimorphism in Jordanians by Discriminant Function Analysis
}

\author{
Evaluación Osteométrica de Diversos Rasgos Morfológicos Mandibulares para el \\ Dimorfismo Sexual en Jordanos Mediante el Análisis de Funciones Discriminantes
}

Wala M. Amin

AMIN, W. M. Osteometric assessment of various mandibular morphological traits for sexual dimorphism in Jordanians by discriminant function analysis. Int. J. Morphol., 36(2):642-650, 2018.

SUMMARY: The aim of this study was to analyze the sexual dimorphism in the mandibles of Jordanians and derive a population specific equation for sex prediction. The employed sample comprised 270 cone beam computed tomography (CBCT) images of Jordanians (147 males and 123 females) aged 27-55 years. The images were rendered to 3D surface models, using customized software that provided various views for each mandible, on which measurements made of nine parameters (ramus height, right and left coronoids height, mandibular length, gonial angle, Intergonial breadth, Intercondylar breadth, mental and mandibular foramena) for the analysis of sex identification. The collected data sets were treated statistically using the Statistical Package SPSS version-21. Canonical discriminant function analysis was used to specify a parameter or combination of parameters that best separate the two sexes. Stepwise analysis together with leave-one-out classification procedure was applied (utilizing the Wilks lambda method), which identified six parameters that formed the best combination most precisely predicting sex. It also identified the predictors' coefficients from which a predictive equation for the Jordanian population was derived. The discriminant function group centroid discriminant scores for males and females and the sectioning cut-score were also defined. According to the equation, the function score for any set of measurements that is above the cut score is probably for a male individual whereas a score that was below the cut score is probably for a female subject.

KEY WORDS: Sexual dimorphism; Sectioning cut-score; Jordanian population; Morphological traits.

\section{INTRODUCTION}

The morphological features of human skeletal remains contributed to the evolution of forensic medicine that used these features in accurate detection of sex, among many other identification concerns. The differences between male and female skeleton are best reflected in the pelvis and the mandible. The two bones have been employed in the studies that attempted to define differences arising from genetically sex-linked growth and development. Studies that used the mandible evaluated various mandibular traits and assessed their validity for use as sex identifiers. Morphometric measurements made on dry mandibles (Ongkana \& Sudwan, 2009; Vinay et al., 2013; Datta et al., 2015) or on orthopantomographs (OPT) (Indira et al., 2012) or on mandibular images obtained by cone beam computed tomography (CBCT) (Gamba et al., 2016) revealed that osteometric parameters that included ramus height and breadth, coronoid height, mandibular length, bigonial breadth, and bicondylar breadth showed significant difference between males and females. Male parameters were significantly higher than female. It was believed that the difference between sexes in the magnitude of exerted masticatory forces that arise from differences in size, strength and angulation of the masticatory muscles could account for the expression of such mandibular dimorphism. Thus, the potential of these parameters as sex predictors was emphasized.

There had been other mandibular traits evaluated in the challenge of defining accurate dimorphic sex predictors. Among them was the position of the mental foramen relative to the height of the body of the mandible. Wical \& Swoope (1974) reported that resorption of the mandibular alveolar ridge occurs mainly above the mental foramen and that the distance from the foramen to the inferior margin of the mandible remains relatively constant throughout life. Rashid \& Ali (2011) and Chandra et al. (2013) reported that the 
vertical position of the mental foramen was significantly higher in male than in female subjects. Thakur et al. (2014) found that the height of the mandible at the mental foramen region and the distance from the superior margin of the foramen and the alveolar crest were significantly higher in males compared to females, it was suggested, therefore, that these traits can be used to determine sex.

The position of the mandibular foramen and its validity for sex determination was assessed by Rashid \& Ali who reported that the vertical position of the mandibular foramen is significantly higher on male patients' radiographs than on females. It was stated "the linear measurements to mandibular foramen's vertical position can be used to predict male sex and differentiate it from female". Jalili et al. (2010) reported significant differences existed between sexes in the position of mandibular foramen both in the vertical and horizontal planes; with mean values of measured distances for males being significantly higher than for females.

Some previous investigations used direct measurements on dry mandibles (Franklin et al., 2008; Ongkana \& Sudwan; Vinay et al.; Datta et al.). Other studies employed Orthopantomographic (OPT) images of mandibles (Rashid \& Ali; Indira et al.; Chandra et al.; Thakur et al.). Recent studies utilized Cone Beam Computerized Tomography (CBCT) scanned images of mandibles (Gahleitner et al., 2003), a technique that was claimed of yielding highly accurate results (Gamba et al.).

The present study was carried out with the objectives of, firstly, evaluating the role of sex on the morphometric characteristics of various mandibular traits and, secondly, to formulate a population specific equation for Jordanians which delineates the most powerful mandibular parameters in sex determination.

\section{MATERIAL AND METHOD}

The investigated sample comprised 270 cone-beam computed tomography (CBCT) images of Jordanian adult patients (147 females and 123 males) whose age ranged between 27 and 55 years. The studied subjects were selected from a larger group of patients who were listed for implant retained prostheses. The exclusion criteria involved images with gross artifacts, presence of bone pathology, history of systemic disease affecting bone metabolism, history of mandibular fracture in the studied area, history of orthodontic treatment, absence of premolars either congenitally or extracted due to impaction, periapical lesions or apical rarefactions involving premolars, presence of supernumerary teeth.
Prior to conducting the investigation, and in compliance with the policy of the Clinical Research Authority at the Jordan University Hospital (JUH), signed written informed consents were obtained from all the subjects selected for the study. They were made aware that their CBCT images were included in this investigation. The experimental protocol was examined and approved by the Ethics Committee and was, therefore performed in accordance with the ethical standards laid down in 1964 Declaration of Helsinki (World Medical Association, 1964).

The CBCT images were acquired with a WhiteFox scanner (WhiteFox, de Götzen SrL ITALY) set at a current voltage of $105 \mathrm{Kv}$ and $9.00 \mathrm{~mA}$, the scan time was set at 9.0 seconds. The CBCT data were exported from the WhiteFox software (WhiteFox Control 3D-00022, version 2.11.1) in DICOM multi-file format and imported into a custom-made "SolidPlanner Pro" software version 3.2, "Solid Models Co., Amman Jordan" (Amin \& Saleh, 2015) on a Pavilion dv6 Laptop (HP USA) with a dedicated 1GB video card (Rad con HD 6750 AMD). All measurements were performed on the 3D surface models of the mandibles on a 17-in, high resolution LCD Laptop color screen. The purpose-designed software (SolidPlanner) converted the DICOM images into 3D surface models of the scanned skulls using the marching cubes algorithm based on surface rendering. Bone surface of the mandibles was extracted from the 2D CBCT images by extracting iso surfaces of Hounsfield values of 3000 . The customized "SolidPlanner" surface rendering software provided various views of the skull, including the mandible, by rotating and translating the rendered image.

Morphometric measurements. The mandibular traits employed in this evaluation included landmarks on the body and ramus of the mandible (Figs. 1 and 2) and (Table I) and measurements for locating the exact position of both the mental and mandibular foramina (Fig. 3) and (Table II). Linear measurements were carried out on thirteen parameters and one angular measurement made on the gonial angle.

Measurements of the different parameters were carried out on three-dimensional converted CBCT images of each mandible of the entire sample. Measurements of the images were executed using a high-resolution screen computer.

Position of the mental and the mandibular foramina. Eight distances four for mental and four for mandibular foramina were measured in each mandible (Figs. 3 and 4) and (Table II).

Statistical Analyses. Statistical analyses of the various data sets were carried out using the Statistical Package SPSS 

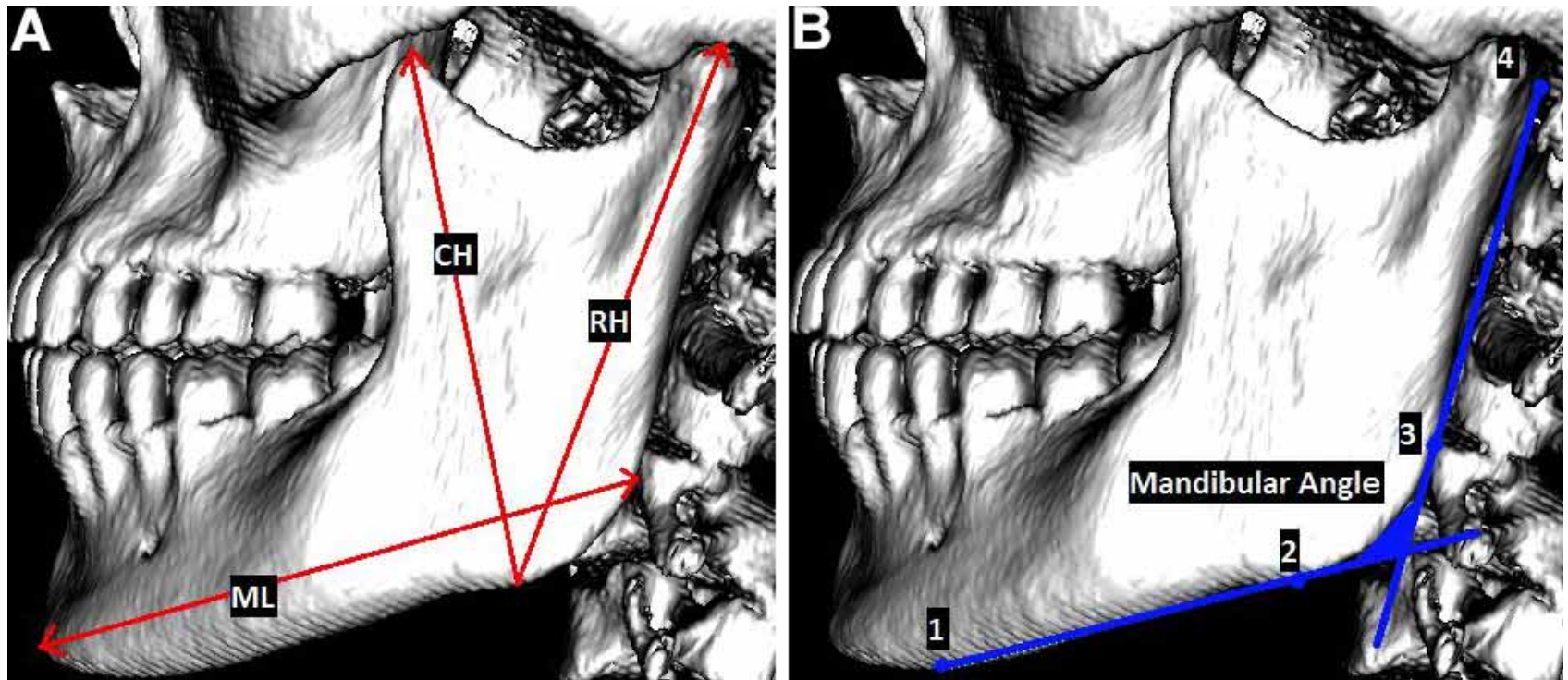

Fig. 1. (left) - illustrating the mandibular traits employed- ramus height "RH" coronoid height "CH", mandibular length "ML". (B) Mandibular "gonial" angle "GA".
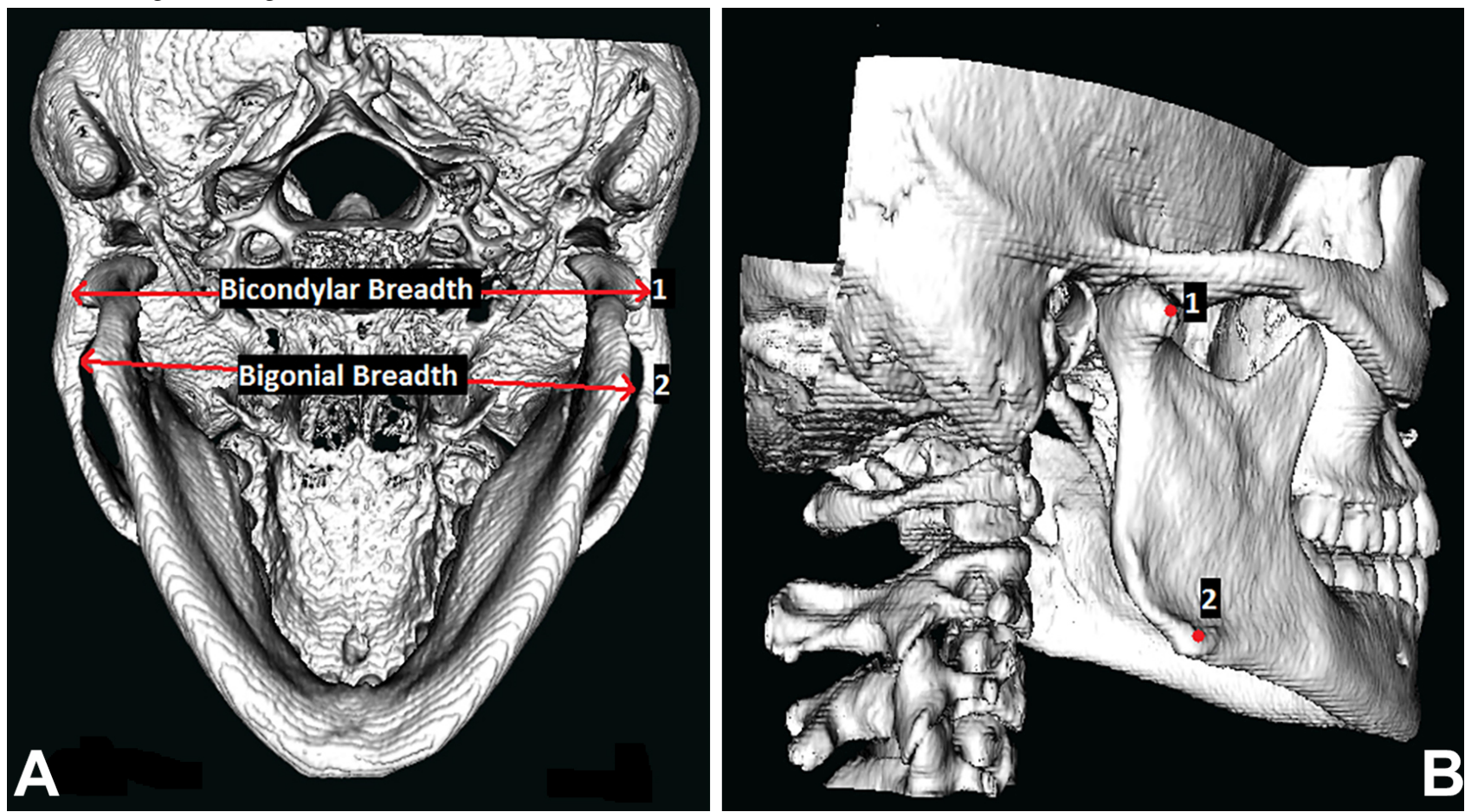

Fig. 2. Illustrating Intercondylar distance (1) and Intergonial distance (2).

Table I. Description of the evaluated parameters of the body and ramus of mandibles.

Ramus height (RH)

Mandibular length (ML)

Coronoid height $(\mathrm{CH})$

Mandibular gonial angle (GA)

Bicondylar breadth (BC-B)

Bigonial breadth (BG-B)
The direct distance from the highest point on the mandibular condyle to gonion (Fig. 1 left)

The distance between a tangent of the anterior margin of the chin and a tangent of the posterior margin of ramus (Fig. 1-left).

The distance between coronion and the lower border (base) of mandible (Fig. 1 left).

Angle formed between the inferior border of the mandible and the posterior margin of the ramus (Fig. 1-right).

The straight distance between the most lateral points on the two condyles (Fig. 2).

The straight distance between two gonia (Fig. 2) 


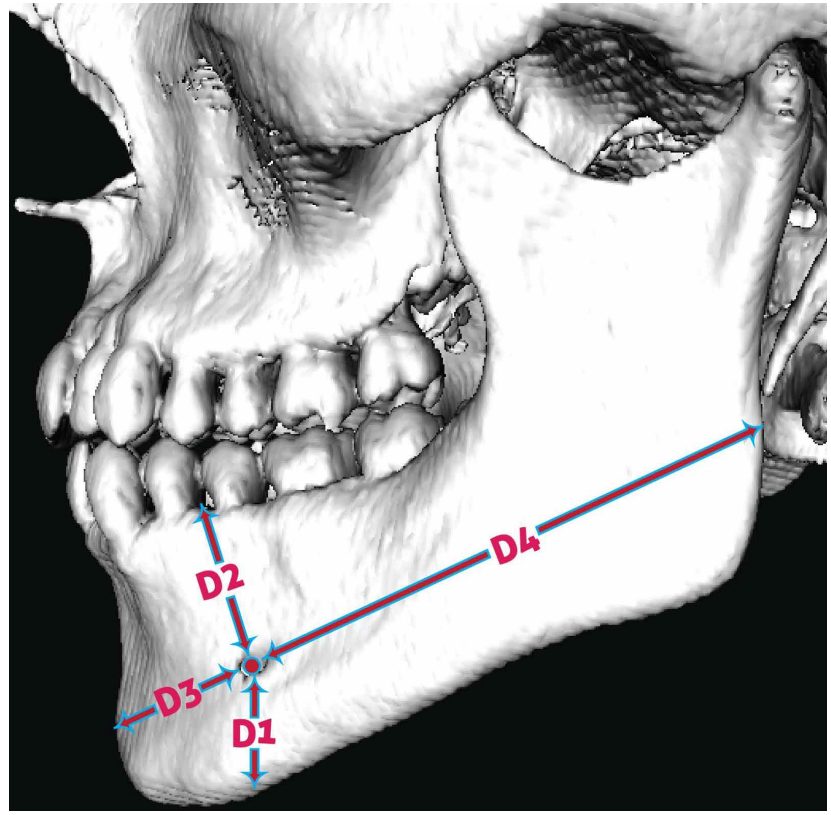

Fig. 3. Illustrating the position of the mental foramen and the distances measured from its center to alveolar crest, base of mandible, and anterior and posterior margins of ramus. version-21 (Statistical Package for Social Studies; SPSS Ltd, Fountain Valley, CA 92708 USA). The parametric data sets were recorded and the mean and standard deviation of various sets derived. The initial comparison made was between the sides (left and right) of the mandibles of the entire sample using student t- test. Descriptive statistics of the mandibular measurements were carried out using canonical discriminant function analysis to specify a parameter or combination of parameters that best separate the two sexes. For this purpose, stepwise discriminant function analysis was used (utilizing the Wilks lambda method). A leave one out classification procedure was applied to demonstrate the accuracy of the analysis. The statistical treatment was conducted at $95 \%$ confidence level.
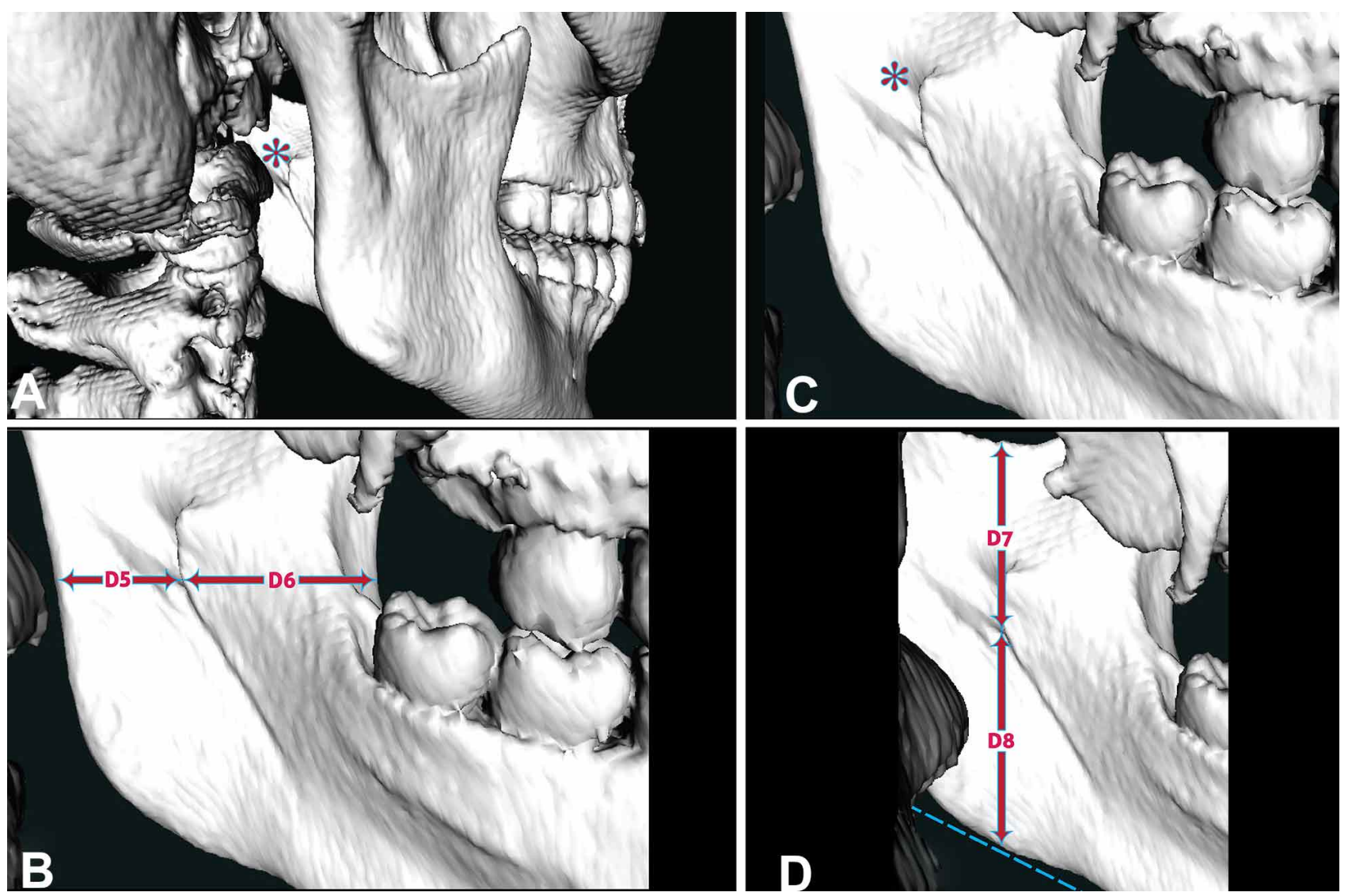

Fig. 4. (A) and (B) Marking the position of mandibular foramen (asterisk). (C) Illustrating the mandibular foramen position relative to the posterior margin of ramus, and to anterior margin of ramus. (D) Illustrating position of foramen relative to deepest point of mandibular notch and to base of mandible. 
Table II. Distances measured for localizing the position of mental and mandibular foramina.

\begin{tabular}{ll}
\hline D1 (MF-IB) & $\begin{array}{l}\text { Distance between the center of the mental foramen perpendicular to a tangent along the lower margin of the } \\
\text { body of the mandible (Fig. 3). }\end{array}$ \\
D2 (MF-AC) & $\begin{array}{l}\text { Distance between the center of mental foramen and the superior limit of alveolar crest (Fig. 3). } \\
\text { D3 (MF-SM) }\end{array}$ \\
Distance from the c enter of the mental foramen and the symphasis mentalis (Fig. 3). \\
D4 (MF-PBR) & $\begin{array}{l}\text { Distance from the c enter of the mental foramen to the posterior margin of mandibular ramus (Fig. 3). } \\
\text { D5 (MndF-PBR) }\end{array}$ \\
$\begin{array}{l}\text { Distance between the deepest point of the posterior border of the ramus to the center of the mandibular } \\
\text { foramen (Fig. 4C). } \\
\text { Distance between the deepest point of the anterior border of the ramus to the center of the mandibular } \\
\text { foramen (Fig. 4C). }\end{array}$ \\
Dertical distance between the deepest point on the mandibular notch to the center of the mandibular for amen \\
(Fig. 4D).
\end{tabular}

\section{RESULTS}

A comparison made between the two sides (right and left) of the employed mandibles, using paired Student t-test, showed no significant difference existed between the sides in the mean values of all the measured fourteen variables. The only exception was the coronoid height " $\mathrm{CH}$ " where the difference between sides was significant ( $\mathrm{p}=0.014)$ (Table III).

This result entailed considering the two coronoid processes CHRt and CHLt as independent parameters in the statistical analyses that followed.

The descriptive statistics of all parameters, the six linear and one angular measurements that were related to the mandibles' body and ramus; and the eight linear measurement that were related to the position of the mental and mandibular foramina, showed significant differences existed between sexes $(\mathrm{p}<0.05)$ in all measurements of the body and ramus, and in four out of eight measurements (D2, D4, D6, D8) that were related to the position of the mental and mandibular foramena (Table IV).

The results of the measurements indicated that means of eleven out of fifteen parameters dimensions were significantly higher for males compared to females. Comparison of measurements mean differences between males and females are illustrated in Figure 5.

Implementing the discriminant function (DF) analysis approach yielded results with classification accuracies that ranged between $56.0 \%$ for (D1) and (D3) parameters and $81.8 \%$ for gonial angle (GA), the best single predictor of sex of all measurements. In addition to the gonial angle, the DF analysis pointed out five other parameters that were found expressing the greatest sexual dimorphism. These, five

Table III. Shows mean ( $\mathrm{mm}$ ) and standard deviation values of the measured parameters on both sides of the employed mandibles of males and females.

\begin{tabular}{lccccccc}
\hline Measurements & RT & \multicolumn{2}{c}{ LT } & \multicolumn{3}{c}{ Tests of Equality of Group Means } \\
& Mean & SD & Mean & SD & Wilks' Lambda & F & Sig. \\
\hline ML & 92.7385 & 5.04999 & 92.755 & 4.99664 & 1.000 & 0.000 & 0.983 \\
GA (Ø) & 141.002 & 13.0959 & 142.483 & 6.45963 & 0.995 & 0.864 & 0.354 \\
RH & 65.1894 & 17.5255 & 63.3628 & 5.88649 & 0.995 & 0.820 & 0.367 \\
CH & 67.8770 & 6.03818 & 65.6435 & 5.65074 & 0.964 & 6.127 & $0.014(*)$ \\
D1 & 12.5952 & 1.65656 & 13.1036 & 1.74444 & 0.978 & 3.753 & 0.054 \\
D2 & 14.8384 & 5.84012 & 13.9143 & 2.57410 & 0.990 & 1.761 & 0.186 \\
D3 & 29.5172 & 11.3201 & 30.3996 & 21.58143 & 0.999 & 0.110 & 0.740 \\
D4 & 66.1966 & 5.08561 & 64.7904 & 9.62232 & 0.992 & 1.402 & 0.238 \\
D5 & 18.3863 & 3.70096 & 19.1178 & 16.11389 & 0.999 & 0.164 & 0.686 \\
D6 & 22.4669 & 3.49032 & 21.5432 & 3.25474 & 0.981 & 3.147 & 0.078 \\
D7 & 19.3523 & 2.80904 & 19.3010 & 3.06909 & 1.000 & 0.013 & 0.910 \\
D8 & 48.5989 & 4.81273 & 48.1191 & 4.81373 & 0.997 & 0.417 & 0.519 \\
\hline
\end{tabular}


Table IV. Showing mean ( $\mathrm{mm}$ ) and standard deviation values of the measured variables, indicating "Wilks Lambda", and associated univariate ' $F$ ' ratios for both sexes, and indicating the classification accuracy of each parameter.

\begin{tabular}{|c|c|c|c|c|c|c|c|c|}
\hline \multirow[t]{2}{*}{ Measurements } & \multirow{2}{*}{$\begin{array}{c}\text { Female } \\
\text { Mean }\end{array}$} & \multicolumn{3}{|c|}{ Male } & \multicolumn{3}{|c|}{ Tests of Equality of Group Means } & \multirow{2}{*}{$\begin{array}{l}\text { Classification } \\
\text { accuracy } \%\end{array}$} \\
\hline & & SD & Mean & SD & Wilks' Lambda & $\mathbf{F}$ & Sig. & \\
\hline BCB & 116.58 & 10.96 & 121.84 & 5.40 & 0.916 & 16.490 & 0.000 & $73.5 \%$ \\
\hline BGB & 92.16 & 4.47 & 98.69 & 5.82 & 0.713 & 151.283 & 0.000 & $81.2 \%$ \\
\hline ML & 90.00 & 3.88 & 95.77 & 6.48 & 0.770 & 53.402 & 0.000 & $75.7 \%$ \\
\hline GA & 147.06 & 6.34 & 118.28 & 22.23 & 0.555 & 143.597 & 0.000 & $81.8 \%$ \\
\hline RH & 62.71 & 4.85 & 67.68 & 6.39 & 0.837 & 34.940 & 0.000 & $71.3 \%$ \\
\hline CH Rt & 70.18 & 12.49 & 73.54 & 10.16 & 0.979 & 53.402 & 0.049 & $59.1 \%$ \\
\hline CH Lt & 51.63 & 13.27 & 70.40 & 5.52 & 0.542 & 72.104 & 0.000 & $75.7 \%$ \\
\hline D1 & 12.62 & 1.52 & 13.20 & 1.53 & 0.965 & 3.008 & $\left.0.087 i^{*}\right)$ & $56.0 \%$ \\
\hline D2 & 13.38 & 2.24 & 15.62 & 4.79 & 0.910 & 8.064 & 0.005 & $65.5 \%$ \\
\hline D3 & 31.61 & 17.04 & 27.87 & 5.67 & 0.980 & 1.636 & $\left.0.204 i^{*}\right)$ & $56.0 \%$ \\
\hline D4 & 62.55 & 6.05 & 69.23 & 4.43 & 0.721 & 31.712 & 0.000 & $70.2 \%$ \\
\hline D5 & 17.45 & 3.17 & 20.32 & 12.14 & 0.971 & 2.421 & $0.124\left(^{*}\right)$ & $57.1 \%$ \\
\hline D6 & 21.41 & 2.86 & 22.78 & 3.41 & 0.953 & 4.036 & 0.048 & $60.7 \%$ \\
\hline D7 & 19.00 & 2.77 & 19.92 & 2.33 & 0.969 & 2.611 & $\left.0.110 c^{*}\right)$ & $58.3 \%$ \\
\hline D8 & 46.34 & 3.79 & 51.02 & 4.47 & 0.753 & 26.895 & 0.000 & $73.8 \%$ \\
\hline
\end{tabular}

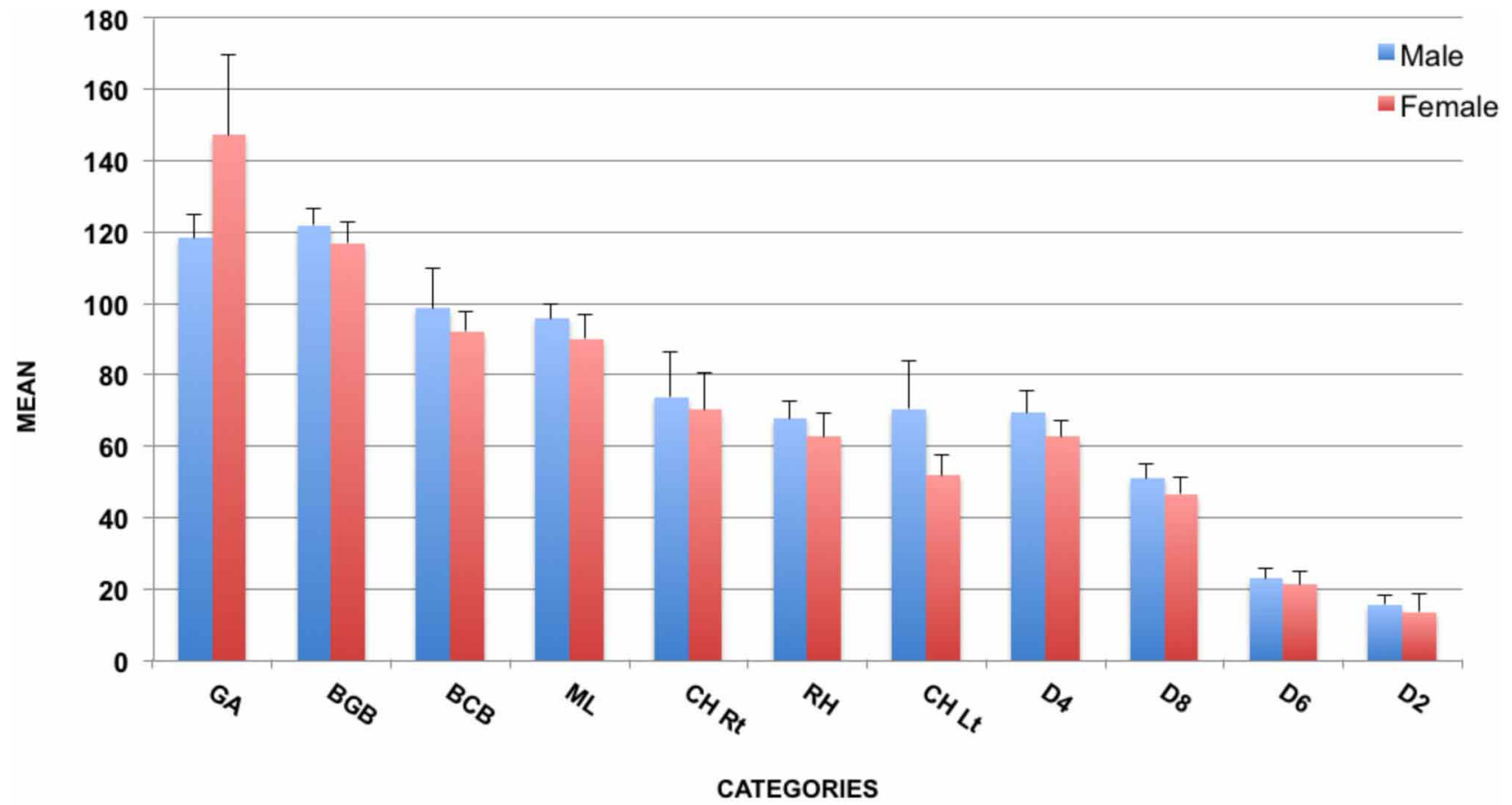

Fig. 5. Illustrating mean measurements in males and females. Error bars indicate values of standard deviations.

parameters together with the gonial angle $(\mathrm{GA})$ were found forming the best combination of parameters most precisely depict the best prediction of sex. Among those selected five, three parameters were related to the body and ramus of the mandible, namely, the bigonial breadth (BGB) with an 'Fstatistic' value of 151.3 and a classification accuracy of 81.2 $\%$; the left and right coronoid height (CHLt, CHRt) with an
'F-statistic' value and classification accuracy of 72.1, 75.7 $\%$ respectively for the first and an 'F-statistics' and classification accuracy of $53.4,59.1 \%$ respectively for the second. The other two parameters that were identified by the DF analysis were related to the position of the mental and mandibular foramina, namely, (D4), the measured distance from the center of the mental foramen to the poste- 
Table V. The outcome of the stepwise discriminant analysis indicating the coefficients of the six best predictors of sex.

\begin{tabular}{lc}
\hline Parameter & Coefficient \\
\hline Bigonial Breadth $(\mathrm{BGB})$ & 0.320 \\
Right coronoid height $\left(\mathrm{CH}_{\mathrm{Rt}}\right)$ & 0.244 \\
Left coronoid height $\left(\mathrm{CH}_{\mathrm{Lt}}\right)$ & 0.715 \\
Gonial angle $(\mathrm{GA})$ & -0.626 \\
Distance between center of mental foramen and superior al veolar crest (D4) & 0.667 \\
Distance between center of mandibular foramen and inferior margin of mandible (D8) & 0.573 \\
\hline
\end{tabular}

rior margin of the mandibular ramus, and (D8), the measured distance between the center of mandibular foramen and the inferior edge of the mandible, with an 'F-statistics' value and classification accuracy of 31.7 and $70.2 \%$ respectively for the first and 26.9 and $73.8 \%$ for the second.

The discriminant analysis yielded the coefficients of the six best predictors selected by the stepwise analysis (Table V).

The discriminant function predictive equation derived from the coefficients of the six best predictors (Table V) selected by stepwise analysis is:

$\mathrm{DF}=0.320 * \mathrm{BGB}+0.244 * \mathrm{CHRt}+0.715 * \mathrm{CHLt}+(-0.626) *$ $\mathrm{GA}+0.667 * \mathrm{D} 4+0.573 * \mathrm{D} 8$
The discriminant function group centroid discriminant score for males is equal to 1.12 and that for females is equal to -0.989 .

The sectioning point is:

$$
\text { Cut score }=[1.12+(-0.989)] / 2=0.067
$$

According to the equation, the discriminant function score for any set of measurements that is above the cut score is probably for a male individual whereas a score that was below the cut score is probably for a female subject.

Values of the predictive classification accuracies resulted from direct discriminant analysis and leave-oneout classification are summarized in Table VI.

Table VI. Presenting the prediction accuracy.

\begin{tabular}{llrrrrr}
\hline & Classification & \multicolumn{2}{c}{ Cross } & \multicolumn{2}{c}{ Classification accuracy } & \multicolumn{2}{c}{ Cross validated } \\
Parameter & accuracy & validated & Male & Female & Male & Female \\
\hline All the selected best predictors & $86.7 \%$ & $83.3 \%$ & $91.3 \%$ & $83.8 \%$ & $87.0 \%$ & $81.1 \%$ \\
\hline
\end{tabular}

\section{DISCUSSION}

The present investigation was planned with two tasks, the first, finding out whether the mandible possesses a sex prediction potential in the Jordanian population, and if it proves so, then the second task was, formulating a population specific equation for Jordanians from the most powerful mandibular parameters that prove effective sex predictors. The mandible, more than other bones, has been extensively employed in research in many disciplines, particularly, forensic and legal medicine, because of this bone's strength that makes it often recovered largely intact. The recent advances in research in the field of radiology and radiographic imaging helped researchers utilize modern techniques for expanding their research by involving antemortem samples.

This investigation was carried out using 3D reconstructed models of mandibles obtained from CBCT scanned images of our patients for whom all linear and angu- lar osteometric measurements were made using a computerguided program, the accuracy of its measurements is known to be submillimeter accurate (Amin \& Saleh). Earlier studies (Gamba et al.) praised the effectiveness and accuracy of this technique and recommended the use of 3D CBCT images for sexual prediction. The results of the present study showed that the mean values of thirteen out of the fourteen evaluated parameters were not significantly different between right and left sides of the employed mandibles. This was in agreement with the findings of previous studies reported by Rashid \& Ali and those by Chandra et al. The exception was in the height of the coronoid process where the right side coronoid was found higher than the left coronoid in both sexes, possibly because of more use of the right side, which is associated with more contraction of the temporalis muscle, a strong elevator muscle of mastication, that is directly attached to the coronoid process. 
It was evident in the results of the present study that females' mandibles were smaller compared to mandibles of their male counterparts in almost all parameters, particularly, those related to mandibular ramus and condyle. These results confirmed previously reported findings (Humphrey et al., 1999; Franklin et al.; Indira et al.) that established the usefulness of mandible for determination of sex. It is believed that bone deposition, or resorption seems to have a potential for becoming sexually dimorphic. Therefore, mandibular ramus and condyle are generally the most sexually dimorphic as they are the sites associated with the greatest morphological changes in size and remodeling during growth. Dimorphism in mandible is obviously reflected in its shape and size, and the expression of mandibular dimorphism is, certainly, influenced by the relative development of muscles of mastication, as masticatory forces exerted are different for males and females (Franklin et al.). It is a known fact that in adult phase, the rate and speed of growth are bigger in men with the results that craniofacial dimensions are 5-9 \% bigger when compared to women. Bone growth in the adult phase is controlled by multiple factors. Among these factors are sex hormones, such as, estrogen and progesterone that can influence in the growth rate and developmental stages of male and female mandibles. Since females reach puberty earlier than males, development of their mandible and skull appear to either stop or slow down earlier than that in maturing males, thus contributing to the development of craniofacial morphological differences between sexes (Hu et al., 2006; Ongkana \& Sudwan). A further controlling factor is the muscular tension, which is considered an inductive factor of bone formation. The contraction of the masticatory muscles, particularly, the elevating muscles attached to the mandible, exert tension throughout the mandibular ramus. Men exert stronger masticatory force than women, and consequently induce more growth of bone on the sites of their muscular influence on the mandibular ramus. This explains why mandibular condyle and ramus, specifically the ramus, are the most sexually dimorphic. The results clearly revealed that men take the lead in the mean values of all the assessed mandibular parameters except the gonial angle, the mean values of which are more in females than in males. The present results revealed that the mean value of the gonial angle for females was approximately 20 degrees larger than that for males. This was consistent with earlier findings by Casey \& Emrich (1988) who reported that women possess more obtuse gonial angle than men. This difference could be because subjects with maximum masticatory force have more acute gonial angle (Bhardwaj et al., 2014); on average men have greater masticatory force than do women. Results of this investigation also showed that the mean value of the left side gonial angle was about 2 degrees larger than the right side angle, possibly because of more use of right side.
In this study, eleven out of fifteen measured mandibular variables showed statistically significant differences between sexes, indicating that mandible expresses strong sexual dimorphism, and can, therefore, be considered an efficient sex predictor for Jordanians. Application of the discriminant function analysis has identified six parameters that were found forming the best combination most precisely depicting and accurately predicting sex, scoring an overall prediction accuracy of $86.7 \%$. Several previous studies from various countries have investigated the sexual dimorphism of the mandible and employed almost the same mandibular parameter to those used in this study but came up with different levels of prediction accuracy. Giles (1964), measured mandibles of American Whites and Blacks from both sexes and reported mandibular ramus height and it's minimum as well as maximum breadth as highly significant, with an accuracy of $85 \%$. Steyn \& Iscan (1998) reported achieved an accuracy of $81.5 \%$ with five mandibular parameters (i.e., bigonial breadth, bicondylar breadth, mandibular length, gonial angle and minimum ramus breadth) in South African Whites. Dayal et al. (2008) found mandibular ramus height to be a significant sex predictor achieving $75.8 \%$ accuracy in their study on South African Blacks. Kharoshah et al. (2010) assessed six mandibular parameters using discriminant function analysis in Egyptian population and reported that only three parameters (bicondylar breadth, gonial angle and ramus breadth) showed sexual dimorphism with $83.9 \%$ accuracy. Similar study was carried out on Brazilian population (Gamba et al.) and employed the same mandibular variables used in the Egyptian study, except that the mandibular ramus breadth variable was not selected by the logistic regression test applied in the Brazilian investigation, which scored with the remaining variables an accuracy rate of $95.1 \%$. This indicates that the morphological characteristics of the mandible are different in different populations, which may be explained by different eating habits. Saini et al. (2011) studied mandibles of adult North Indians using five variables and reported an overall prediction rate of $80.2 \%$. They found the best parameters were coronoid height, condylar height and projective ramus height, whereas, the breadth measurements were not very dimorphic in their sample of North Indians. It is noteworthy, that those same breadth measurements that were not very dimorphic in North Indian population were found to be best parameters in the South Indian population (Indira et al.) and also found to be very dimorphic in other osteometric studies conducted on American Whites and Blacks (Giles). This can be attributed to the differences in the musculoskeletal development and to differences related to a different growth rates in males and females (Humphrey et al.). The present study on Jordanian population used the stepwise discriminant analysis that selected the best predictors of sex and achieved a reliable level of accuracy $(86.7 \%)$ in sex estimation. It should be noted that despite the fact that other researchers from 
countries other than Jordan used most of the mandibular parameters used in this study but the outcome was never identical. This reality lead to the belief that socioenvironmental factors, such as, nutrition, climate, pathologies, etc., influence the development of bone (Saini et al.). The literature is replete of studies that demonstrated the different skeletal characteristics in each population and emphasized the need for population-specific osteometric standards for sex determination (Giles; Saini et al.).

CONCLUSION.This study showed that all the assessed mandibular parameters in males were statistically different than in females, which made possible the use of these parameters in distinguishing the sex of Jordanian mandibles. It was revealed that mandibular morphometric measurements made on 3D CBCT images achieve high accuracy for sexual prediction, thus, recommending the use of such images for effective and accurate anthropometric measurements. The results of the applied statistical treatment proved reliability and confirmed accuracy of the discriminant function analysis approach applied in our sample. Hence, validated the formula developed in this study for the Jordanian population that can be used for sexual prediction, and be of a value in forensic dentistry setting.

AMIN, W. M.Evaluación osteométrica de diversos rasgos morfológicos mandibulares para el dimorfismo sexual en jordanos mediante el análisis de funciones discriminantes. Int. J. Morphol., 36(2):642-650, 2018.

RESUMEN: El objetivo de este estudio fue analizar el dimorfismo sexual en las mandíbulas de los jordanos y derivar una ecuación específica de la población para la predicción del sexo. La muestra consistió en 270 imágenes de tomografía computarizada de haz cónico (CBCT) de jordanos (147 hombres y 123 mujeres) con edades entre los 27 y 55 años. Las imágenes se representaron en modelos de superficie 3D, utilizando software personalizado que proporcionó varias imagenes para cada mandíbula, en las que se midieron nueve parámetros (altura de la rama, altura de los procesos coronoides derecho e izquierdo, longitud mandibular, ángulo gonial, amplitud intergonial, amplitud intercondilar y foramen mandibular) para el análisis de la identificación de sexo. Los conjuntos de datos recopilados se trataron estadísticamente utilizando el programa estadístico SPSS versión-21. El análisis de función discriminante canónica se utilizó para especificar un parámetro, o una combinación de parámetros que separaran mejor los dos sexos. Se aplicó el análisis por pasos junto con el procedimiento de clasificación de dejar salir uno (utilizando el método de Wilks lambda), que identificó seis parámetros que formaban la mejor combinación que predecía con mayor precisión el sexo. También se identificó los coeficientes de los predictores a partir de los cuales se obtuvo una ecuación predictiva para la población jordana. Se definieron además, los puntajes discriminantes centroide del grupo para hombres y mujeres, además del puntaje de corte seccional. De acuerdo con la ecuación, el puntaje de la función para cualquier conjunto de medidas que está por encima del puntaje de corte es probablemente para un individuo masculino, mientras que un puntaje que estaba por debajo del puntaje de corte, probablemente era femenino.

PALABRAS CLAVE: Dismorfismo sexual; Score corte por sección; Población jordana; Rasgos morfólogicos.

\section{REFERENCES}

Amin, W. M. \& Saleh, M. W. M. Accuracy of a customized volumetric rendering program in linear measurement of cone beam and multi-slice computed tomography derived three-dimensional images. J. Oral Maxillofac. Radiol., 3(2):33-8, 2015.

Bhardwaj, D.; Kumar, J. S. \& Mohan, V. Radiographic evaluation of mandible to predict the gender and age. J. Clin. Diagn. Res., 8(10):ZC66-9, 2014.

Casey, D. M. \& Emrich, L. J. Changes in the mandibular angle in the edentulous state. J. Prosthet. Dent., 59(3):373-80, 1988.

Chandra, A.; Singh, A.; Badni, M.; Jaiswal, R. \& Agnihotri, A. Determination of sex by radiographic analysis of mental foramen in North Indian population. J. Forensic Dent. Sci., 5(1):52-5, 2013.

Datta, A.; Siddappa, S. C.; Gowda, V. K.; Channabasappa, S. R.; Shivalingappa, S. B. B.; Srijith \& Dey, D. A study of sex determination from human mandible using various morphometrical parameters. Indian J.Forensic Community Med., 2(3):15866, 2015.

Dayal, M. R.; Spocter, M.A. \& Bidmos, M. A. An assessment of sex using the skull of black South Africans by discriminant function analysis. Homo, 59(3):209-21, 2008.

Franklin, D.; O’Higgins, P.; Oxnard, C. E. \& Dadour, I. Discriminant function sexing of the mandible of indigenous South Africans. Forensic Sci. Int., 179(1):84.e1-5, 2008.

Gahleitner, A.; Watzek, G. \& Imhof, H. Dental CT: imaging technique, anatomy, and pathologic conditions of the jaws. Eur. Radiol., 13(2):366-76, 2003.

Gamba, T. de O.; Alves, M. C. \& Haiter-Neto, F. Mandibular sexual dimorphism analysis in CBCT scans. J. Forensic Leg. Med., 38:106-10, 2016.

Giles, E. Sex determination by discriminant function analysis of the mandible. Am.J. Phys. Anthropol., 22:129-35, 1964.

Hu, K. S.; Koh, K. S.; Han, S. H.; Shin, K. J. \& Kim, H. J. Sex determination using nonmetric characteristics of the mandible in Koreans. J. Forensic Sci., 51(6):137682, 2006.

Humphrey, L. T.; Dean, M. C. \& Stringer, C. B. Morphological variation in great ape and modern human mandibles. J. Anat., 195(Pt. 4):491-513, 1999.

Indira, A. P.; Markande, A. \& David, M. P. Mandibular ramus: An indicator for sex determination - A digital radiographic study. J. Forensic Dent. Sci., 4(2):58-62, 2012.

Jalili, M. R. The research of mandibular foramen in panorex X-ray. Pak. J.Biol. Sci., 13(21):1062-5, 2010.

Kharoshah, M. A.; Almadani, O.; Ghaleb, S. S.; Zaki, M. K. \& Fattah, Y. A. Sexual dimorphism of the mandible in a modern Egyptian population. J. Forensic Leg. Med., 17(4):213-5, 2010.

Ongkana, N. \& Sudwan, P. Gender difference in Thai mandibles using metric analysis. Chaing Mai Med.J., 48(2):43-8, 2009.

Rashid, S. A. \& Ali, J. Sex determination using linear measurements related to the mental and mandibular foramina vertical positions on digital panoramic images. J. Baghdad Coll. Dent., 23:59-64, 2011.

Saini, V.; Srivastava, R.; Rai, R. K.; Shamal, S. N.; Singh, T. B. \& Tripathi, S. K. Mandibular ramus: an indicator for sex in fragmentary mandible. J. Forensic Sci., 56 Suppl. 1:S13-6, 2011.

Steyn, M. \& Iscan, M. Y. Sexual dimorphism in the crania and mandibles of South African whites. Forensic Sci.Int., 98(1-2):9-16, 1998.

Thakur, M.; Reddy, K. V. K.; Sivaranjani, Y. \& Khaja, S. Gender determination by mental foramen and height of the body of the mandible in dentulous patients. A radiographic study. J. Indian Acad. Forensic Med., 36(1):13-8, 2014.

Vinay, G.; Gowri, S. R. M. \& Anbalagan, J. Sex determination of human mandible using metrical parameters. J. Clin. Diagn. Res., 7(12):2671-3, 2013.

Wical, K. E. \& Swoope, C. C. Studies of residual ridge resorption. I. Use of panoramic radiographs for evaluation and classification of mandibular resorption. J. Prosthet. Dent., 32(1):7-12, 1974.

World Medical Association (WMA). Declaration of Helsinki - Ethical Principles for Medical Research Involving Human Subjects. Helsinki, Proceedings of the 18th General Assembly, 1964.

\section{Corresponding author}

Prof. Wala M. Amin

Faculty of Dentistry

University of Jordan

West Amman Province 11942

Amman - JORDAN

Received:31-12-2017

E-mail: walaamin@gmail.com
Accepted:09-02-2018 